\title{
Mathematical Model of Financial Market Returns and Its Empirical Study Xue Wang ${ }^{1,}$, Qingbao Song ${ }^{2, \text { a }}$ \\ ${ }^{1}$ Changchun Sci-Tech University, Changchun, Jilin, 130600 \\ ${ }^{a}$ email, ${ }^{b}$ email
}

Keywords: Financial Market Interests, Practical Study, Mathematical Model

\begin{abstract}
The yield is a very important economic variable in the process of economic operation and plays a very important role in the financial market. For the financial market, the stability and the change law of the yield are the direct factors that affect the development of the financial industry. To this end, based on the differential equation theory, the discrete market model of financial market returns, by analyzing the discrete mathematical model of the financial market Stability and changes in the law to make a prediction, which play to improve the financial sector macro decision-making accuracy and rationality of the role.
\end{abstract}

\section{Introduction}

The empirical analysis of financial markets in the 1960s and 1970s mostly supported the EMH, but in the 1980s, a large number of empirical studies of financial markets found many of the traditional mainstream financial theory can not explain the vision, such as stock premium mystery, closed Fund puzzles, scale effects and calendar effects. In order to explain these visions, some scholars have applied the research results of psychology and behavior to the research of financial market, put forward a lot of theoretical models and empirical evidence, and become a thriving new field of financial market research. And the 2002 Nobel Prize were awarded to the field of representatives, to promote the development of disciplines in this field, the formation of behavioral finance school.

\section{Significance of the Study of the Distribution of Yield}

Many of the internal and external factors that affect financial markets are complex and difficult to deal with, but the interactions of various factors in financial markets produce many observable results such as price, yield, volume, and market index. The study of the statistical characteristics of these results will help to understand the inherent laws of financial markets and provide a solid theoretical basis for the establishment of various financial theories. As an observable result in financial markets, securities yield is an important concept in financial economics. The most important feature of yield is its randomness and uncertainty. Probability distribution is the basic tool to describe uncertainty. The correct description of the distribution of the yield is directly related to the rationality and effectiveness of the theory of portfolio theory, risk management theory and financial derivative product pricing. Traditional financial theory generally assumes that the distribution of returns satisfies the normal distribution, the modern portfolio theory MTP, and the option pricing theory OTP are established on this hypothesis. However, a large number of empirical studies show that although the distribution of yield is difficult to determine, but certainly not subject to normal distribution, the actual yield distribution there are obvious spikes and thick tail characteristics. In order to explain and describe this typical feature, many scholars have explored many aspects and achieved rich results, but have not yet reached a satisfactory conclusion. The development of behavioral finance provides a new idea for the study of the distribution of yield. On the basis of the hypothesis of behavioral finance theory, the research on the distribution of profitability can deepen the understanding of the law of the operation of real financial market from a new angle.

In the context of the rapid rise of behavioral finance research, this paper takes the subjective distribution model of profitability based on behavioral finance theory as the research topic and tries to analyze the market return rate based on the theory of behavioral finance based on the theory and 
reality of the theory of yield distribution. Based on the distribution model of income distribution, and then establish a behavioral finance research model and method which is independent of the specific psychological phenomenon and has some universality, and its research has relatively independent behavior. The paper analyzes the relationship between the internal factors, the behavior factors and the performance of the securities market, and makes an empirical study on the running characteristics and the market situation in China's securities market.

\section{Financial Market Rate of Return Discrete Mathematical Model}

The basic equation is the basic expression of the liquidity model. In the process of establishing the basic equation, the capital flow between the various sectors or departmental nodes in the whole financial economic network is neglected, and the discrete mathematics applicable to the analysis of the yield of each network node is obtained Equation expression

$$
R i(n+1)-R i(n)=c i \sum_{\substack{j \neq 1 \\ j \neq i}}^{m} \frac{1}{k j i}[(R j(n)-R i(n)]
$$

When the time is $(n+1)$, the difference between the immediate rate of return and the basic rate of return of node i can also be called the relative yield of a node i. Where the basic rate of return is between the nodes there is no capital flow between the yield value, and real-time rate of return there is a significant difference. The difference between $\mathrm{Ri}(\mathrm{n})$ and $\mathrm{Ri}(\mathrm{n}+1)$ is mainly manifested in the moment, ie Equation 1.1 is an expression for the same node. The ci in the formula is a proportional coefficient, which is generally a constant greater than 0 , and its physical meaning is as follows: The immediate rate of return of node i to the degree of capital flow. Therefore, ci can be described as the sensitivity coefficient of node i.

For the basic equation 1.1, the basic rate of return of each node $\mathrm{i}$ involved in the financial network is regarded as a constant, which is quite different from the actual economic operating state, but by this simplification, it is easy for the analyst to rate To make timely dynamic characterization and analysis, although the reliability of the data is low, but its validity can meet the basic needs of financial market rate of return analysis. Therefore, the discrete-time model based on the basic equation can be widely used in the prediction of financial market yield. In addition to Equation 1.1, the formula can be changed to the expression forms of Formulas 1.2 and 1.3, which provides greater convenience for the analysis of market returns in different sectors or financial sectors.

\section{Establishment and Analysis of Circulation Equation for Discrete Mathematical Model}

Compared with the closed financial network, open financial network is a widespread financial market, that is, most of the financial network even said that each financial network has an open feature, but there is a difference in the degree of openness. In the case of the discrete mathematical model, the homogeneous linear case, the nonhomogeneous linear case and the boundary value problem of the expression are analyzed on the basis of the qualitative theory of the difference equation to determine the change of the yield of the specific sector or industry $i$ in the financial market feature. The establishment of discrete time-delay yield-flow equation not only takes into account the openness of financial network, but also takes into account the impact of the past on the present. In view of the expression of the equation, the basic form is the constant difference equation. For different financial markets and the characteristics of capital flows, you can get different conditions of expression. The qualitative analysis of the mathematical model of discrete time lag yields mainly includes the analysis of eigenvalue problem, the analysis of stability and periodic solution, and the analysis of economic significance. The stability and economic significance analysis are the key contents. $(N+T+1)-R(n+T)=M R(n)$ is introduced when the yield stability is analyzed and the m-order block $\mathrm{A}, \mathrm{A}(\mathrm{A})$ of $(\mathrm{T}+1)$ Including the m-order unit matrix I. The discrete pulse yield mathematical model applies to a special financial network model, that is, there is a sudden phenomenon caused by fluctuations in the market, the general expression is based on the above 1.1-1.6 to increase the necessary wave coefficient of the formation of the equation, given 
the pulse The diversity of the disturbance, the discrete pulse yield - the flow equation exists there are more than a dozen or even dozens of expressions, subject to space constraints, here omitted. Qualitative analysis of discrete pulse yield model, mainly in order to determine the pulse perturbation closed network and open financial network yield stability.

\section{Comparative Study on the Establishment of the Benchmark Market}

For any interest rate market economy, the benchmark interest rate plays a very important role. The benchmark interest rate is the interest rate that has a universal reference effect in the financial market. Other interest rates or financial asset prices can be determined based on this benchmark interest rate. In the interest rate market conditions, the financing of financing costs, investors calculate the investment income, the objective requires a generally recognized benchmark interest rate for reference. Under the condition of interest rate marketization, the term structure of the benchmark interest rate measures the relationship between the yield of different expiry date risk-free securities. Its main role is reflected in: at the macro level, to support the macro sector for economic forecasting, to assist the monetary authorities to develop and implement monetary policy; at the micro level, the use of benchmark yield curve can accurately measure the benchmark yield curve outside the transaction Point, find investment opportunities, guide daily investment activities and market risk management activities. The so-called interest rate marketization is related to the government's complete control over interest rates, that is, the interest rate is determined by the supply and demand forces of the market. Consistent with the price of the commodity, the interest rate is determined by the trading behavior between the economic entities of the market. Interest rate marketization should include at least the following aspects:

First, interest rates are determined by the parties involved in financial activities. Financial activity is a financial transaction between the fund surplus department and the capital deficit department. In this transaction process, the two sides of the game on the scale of the transaction price! Price! Repayment period! Guarantee methods and other specific terms of bargaining. The bargaining method may be an interview! Tender, it may be capital supply and demand sides in different customers or service providers between the repeated trade-offs and choices. Second, a sound market-oriented interest rate system should have a reasonable number of structures! Term structure and risk structure. Since interest rates arise from the compensation that is caused by the abandonment of current consumption, the unavoidable, uncertain risk will be a necessary prerequisite for interest rate decisions. Therefore, the complete interest rate system will include a reasonable term structure and risk structure, which it has a significant difference between the pricing of ordinary commodities. Similarly, the parties involved in a financial transaction agree on a specific quantity (or scale) of a transaction (maturity) risk and its specific interest rate level, thereby synthesizing a representative rate structure for the entire financial market. Because the market interest rate system contains a very complex quantity, duration and risk structure, it is necessary for the game subject of financial transactions to have a common knowledge of the market interest rate. This common knowledge, Of the benchmark interest rate. This benchmark interest rate generally by the market trading volume! Financial transactions to accept the main interest rate to play. We see that the benchmark interest rate is at the heart of the market interest rate system. It is not only the anchor of the stable interest rate system, but also the outline of the interest rate system. The whole interest rate system will be adjusted accordingly. According to the practical experience of each country, the ability to act as a benchmark interest rate can only be located at the bottom of the whole interest rate system, the risk is minimal, the most satisfying public liquidity preference, the best way to guide the public, the most convenient central bank operation, conduction effect of the best interest rate. According to the experience of other countries, short-term bond repo rate! Interbank rate or long-term Treasury bond rate is the largest trading volume on the market! Information disclosure is the most fully and therefore the most representative market interest rates, they are easy to become the basis for the development of all other interest rates Standards, but also the basis for measuring the level of market interest rates ups and downs; the central bank through the control of these interest rates can be achieved on the entire interest rate, and even the regulation of the 
economy. Obviously, only to establish an effective benchmark interest rate, interest rate market reform can have a substantial breakthrough, and can get sustained progress. On the other hand, if there is no leading role in regulating the benchmark interest rate, interest rate market reform is lacking in stability and sustainability.

China's interest rate market reform is in progress, managers choose a progressive road, that is, in the informal finance and formal finance in two areas. China's earliest interest rate marketization is in the form of informal finance, which is carried out in the non-state-owned economic sector and the combination of non-state-owned economic sectors and state-owned economic sectors. Historically, the main form is interbank lending and bond repurchase. Interest rates formed in these informal financing transactions are largely market-oriented. At the same time, with the financing process in the process of marketization of interest rates, the central bank's macro-control from the administrative control to the market-oriented control of the transformation process has also made considerable progress. Since 1996, China's interest rate market-oriented reform has experienced four important stages, namely: to open the interbank interest rate; open the bond market interest rates; to achieve the lower limit of loan interest rates, deposit interest rates on the upper limit of the interest rate market Reform the target; to promote the benchmark market interest rate construction, cultivate shibor interest rate curve. This shows that in China, the central bank's market-oriented control system has begun to take shape.

\section{Conclusion}

The factors influencing the financial market are numerous and difficult to deal with. As an observable result in the financial market, the study of the distribution of the yield is of great significance to explore the inherent law of the financial market. Under the framework of traditional mainstream financial theory, the research on the distribution model of yield has achieved rich results, but there are still many problems worthy of study. The rise of behavioral finance provides a new way of thinking about the distribution of yield. Behavioral finance, through the combination of behavioral theory and financial analysis, challenges the effective market hypothesis from the irrational point of view of human decision-making. The basic conclusion is that the market price of securities is determined not only by the internal factors, To a large extent by the actors involved in the behavior of the impact of factors, this effect has a substantive, long-term.

\section{References}

[1] Cheng Kun, Liu Renhe. Interaction between investor sentiment and stock market [J]. Shanghai Economic Research, 2005 (11)

[2] Tao Miao, Xu Yang, Xing Yannan. China's stock market weekend effect empirical study [J]. Commercial times, 2005 (21)

[3] Wang Ning, Mao Ning. New Advances in Psychological Deviation of Bounded Rational Individual Investors [J]. Economic Theory and Economic Management, 2005 (06)

[4] Zhu Konglai, Ni Jie. Experimental Analysis on the Fluctuation Characteristics of Stock Index in China's Stock Market [J] .Journal of Mathematical Statistics and Management, 2005 (03)

[5] Zhu Zhanyu, Wu Zhaofeng. Model effect and reverse effect model considering short selling limit [J]. System Engineering Theory and Practice, 2005 (01) 